\title{
IMPLEMENTASI NORMALISASI DALAM PERANCANGAN DATABASE RELATIONAL
}

\author{
Oleh : \\ Sudi Suryadi \\ Fakultas Teknik Universitas Al- Washliyah Labuhanbatu \\ e-mail : sudisuryadi28@gmail.com
}

\begin{abstract}
ABSTRAK
Dalam merancang sebuah database relasional, untuk kebutuhan sistem informasi dibutuhkan suatu Teknik yang disebut dengan Normalisasi. Dengan adanya teknik ini memungkinkan menghindari terjadinya berbagai anomali data dan tidak konsistensinya sebuah data. Dalam beberapa kasus normalisasi ini sangat penting untuk menunjang kinerja database dan memastikan bahwa data dalam database tersebut aman dan tidak terjadi kesalahan jika mendapat perintah SQL terutama DML yaitu update, insert, dan delete. Normalisasi menggunakan tahap-tahapan dalam penyelesaiannya yang disebut dengan 1NF, 2NF, 3NF, BCNF, 4NF, 5NF, DKNF, 6NF, setiap tahapan-tahapan memiliki ciri-ciri dalam penyelesaiannya.
\end{abstract}

\section{Kata Kunci : normalisasi, relasi, rdms, database}

\begin{abstract}
In design a relational database, for the information system needs needed a technique called Normalization. With this technique it is possible to avoid various data anomalies and the inconsistency of data. In some case this normalization is very important to support the performance of the database and ensure that the data in the database is safe and there is no error if you get SQL commands, especially DML, namely update, insert, and delete. Normalization uses the stages in its settlement called $1 N F, 2 N F, 3 N F, B C N F, 4 N F, 5 N F, D K N F, 6 N F$, each of the stages has characteristics in its completion.
\end{abstract}

\section{Keywords : normalisasi, relation, rdms, database}

\section{PENDAHULUAN}

Menurut Elmasri \& Navathe (2013) database adalah Himpunan kelompok data (arsip) yang saling berhubungan yang diorganisasi sedemikian rupa agar kelak dapat dimanfaatkan kembali dengan cepat dan mudah. Database juga dapat diartikan sebagai kumpulan data yang saling berhubungan yang disimpan secara bersama sedemikian rupa dan tanpa pengulangan (redundansi) yang tidak perlu, untuk memenuhi berbagai kebutuhan, Date C.J. (2014). Database mutlak dibutuhkan pada suatu sistem informasi, dimana data akan disimpan dan diolah untuk menjadi informasi-informasi yang penting bagi suatu perusahaan atau organisasi. Jenis database yang masih sangat banyak digunakan adalah database relasional. Dimana data disimpan didalam baris pada sebuah tabel yang memiliki relasi dengan tabel lain. Pada database relasional terdapat banyak pengaturan yang dikenal dengan primary key, foreign key, record, field/ kolom/ attibute, domain/ data type yang menjaga agar data dapat diproses dengan cepat dan mudah, penghematan ruang menyimpanan, serta data yang dihasilkan akurat, Fathansyah (2012). Dengan perancangan yang bagus dan matang, maka manfaat database tersebut dapat diperoleh. Akan tetapi untuk beberapa kasus tertentu 
dimana perancangan kurang matang, menghasilkan tabel tabel yang kurang baik, maka manfaat database dapat diperoleh. Pada kasus seperti ini, dibutuhkan proses normalisasi database.

\section{KAJIAN LITERATUR}

\subsection{Normalisasi}

Normalisasi adalah proses pembentukan struktur basis data sehingga sebagian besar ambiguity bisa dihilangkan. Tahap Normalisasi dimulai dari tahap paling ringan (1NF) hingga paling ketat (5NF). Biasanya hanya sampai pada tingkat 3NF atau BCNF karena sudah cukup memadai untuk menghasilkan tabel-tabel yang berkualitas baik. Sebuah tabel dikatakan baik (efisien) atau normal jika memenuhi 3 kriteria sebagai berikut :

a) Jika ada dekomposisi (penguraian) tabel, maka dekomposisinya harus dijamin aman (Lossless-Join Decomposition). Artinya, setelah tabel tersebut diuraikan / didekomposisi menjadi tabel-tabel baru, tabel-tabel baru tersebut bisa menghasilkan tabel semula dengan sama persis.

b) Terpeliharanya ketergantungan fungsional pada saat perubahan data (Dependency Preservation).

c) Tidak melanggar Boyce-Code Normal Form (BCNF).

Jika kriteria ketiga (BCNF) tidak dapat terpenuhi, maka paling tidak tabel tersebut tidak melanggar Bentuk Normal tahap ketiga (3rd Normal Form / 3NF). Normalisasi digunakan sebagai teknik analisis data pada database, sehingga dapat diketahui apakah pembuatan tabel - tabel yang terelasi dalam database itu sudah baik. Kondisi sudah baik yaitu suatu kondisi pada saat proses insert, update, delete dan modifikasi pada satu atau beberapa atribut suatu tabel tidak berpengaruh terhadap integritas data yang lain dalam satu hubungan relasi database.

\subsection{Bentuk-Bentuk Normalisasi}

Adapun bentuk-bentuk normalisasi sebagai berikut :

a) Bentuk Normal Tahap Pertama (1st Normal Form / 1NF)

b) Bentuk Normal Tahap Kedua (2nd Normal Form / 2NF)

c) Bentuk Normal Tahap (3rd Normal Form / 3NF)

d) Boyce-Code Normal Form (BCNF)

e) Bentuk Normal Tahap (4th Normal Form / 4NF)

f) Bentuk Normal Tahap (5th Normal Form / 5NF)

g) Domain Key Normal Form (DKNF)

h) Bentuk Normal Tahap (6th Normal Form / 6NF)

Namun dalam prakteknya dalam dunia industri bentuk normalisasi ini yang paling sering digunakan ada sekitar 5 bentuk. Sudah disebutkan bahwa secara teori, bentuk normal suatu relasi bisa sampai ke tingkat lima 5NF, yaitu 1NF - 2NF - 3NF/BCNF - 4NF - 5NF. Tetapi secara praktik dalam dunia nyata, relasi dalam suatu database sudah dibilang baik kalau sudah mencapai 3NF (bentuk normal ketiga). Untuk lebih jelasnya ciri-ciri dari bentuk-bentuk tahapan normalisasi dapat dilihat pada gambar di bawah ini : 


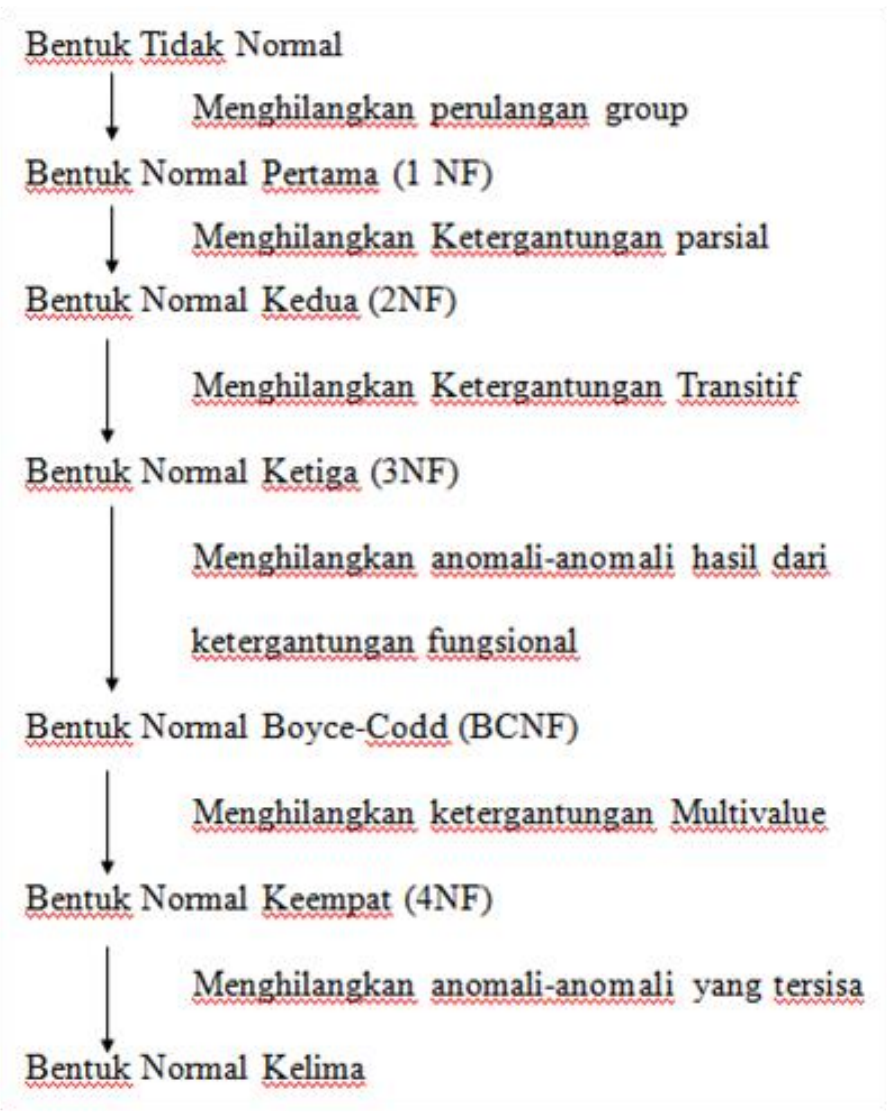

Gambar 1. Bentuk Tahapan Normalisasi

\section{IMPLEMENTASI}

Untuk pengimplementasikan normalisasi ke dalam sebuah rancangan database dapat diikuti langkahlangkah sebagai berikut :

\section{1) Unnormalization Form}

Bentuk yang tidak normal dimaksudkan suatu kumpulan data yang akan diolah yang diperoleh dari formatformat yang beraneka ragam, masih terdapat duplikasi atau pengulangan data, bisa saja tidak sempurna atau tidak lengkap, dan sesuai fakta lapangan. Bentuk ini didapat dari dokumen yang ada dilapangan atau manual dengan atribut bukan nilai sederhana. Untuk lebih jelasnya dapat dilihat pada tabel 1 di bawah ini :

Tabel 1. Unnormalisasi Tabel

\begin{tabular}{|c|c|c|c|c|c|c|c|}
\hline \multicolumn{8}{|c|}{ Tabel Mahasiswa } \\
\hline nim & nama & prodi & kode $\mathrm{mtk}$ & nama mtk & id dosen & nama dosen & nilai \\
\hline \multirow{2}{*}{1234} & \multirow{2}{*}{ Roma } & \multirow{2}{*}{ TI } & T14801 & Sistem Basis Data & SSD & Surya & A \\
\hline & & & T14815 & |Rekayasa Perangkat Lunak & RNW & Ronal & $\mathrm{C}$ \\
\hline \multirow{3}{*}{2345} & \multirow{3}{*}{ Beni } & \multirow{3}{*}{$\mathrm{SI}$} & T14801 & Sistem Basis Data & SSD & Surya & B \\
\hline & & & UN121 & Kalkulus & WHY & Wahyu & $\mathrm{B}$ \\
\hline & & & UN125 & Bahasa Indonesia & SAB & Sabrina & A \\
\hline
\end{tabular}




\section{2) Bentuk Normal Tahap Pertama (1st Normal Form / 1NF)}

Adapun ciri-ciri bentuk normal $1 \mathrm{NF}$ adalah :

a) Jika sebuah tabel tidak memiliki atribut bernilai banyak (multivalued attribute) denga arti harus bernilai tunggal.

b) Jika sebuah tabel tidak memiliki atribut composite atau kombinasinya dalam domain data yang sama. Setiap atribut dalam tabel tersebut harus bernilai atomic (tidak dapat dibagi-bagi lagi).

c) Jika sebuah tabel tidak memiliki atribut turunan/derivatied value.

d) Jika sebuah tabel tidak memiliki record yang bernilai ganda/ redundancy.

e) atribut composite atau kombinasinya dalam domain data yang sama.

f) Setiap atribut dalam tabel tersebut harus bernilai atomic (tidak dapat dibagi-bagi lagi).

Tabel dari unnormalisasi pada langkah pertama dapat dekomposisi menjadi tabel di bawah ini :

Tabel 2. Tabel Mahasiswa Bentuk 1NF

\begin{tabular}{|c|c|c|c|l|c|c|c|}
\hline Tabel Mahasiswa & \multicolumn{1}{|l|}{ nama_mtk } & id_dosen & nama_dosen & nilai \\
\hline nim & nama & prodi & kode_mtk & \multicolumn{1}{|c|}{ natis } & SSD & Surya & A \\
\hline 1234 & Roma & TI & T14801 & Sistem Basis Data & RNW & Ronal & C \\
\hline 1234 & Roma & TI & T14815 & Rekayasa Perangkat Lunak & SSD & Surya & B \\
\hline 2345 & Beni & SI & T14801 & Sistem Basis Data & WHY & Wahyu & B \\
\hline 2345 & Beni & SI & UN121 & Kalkulus & SAB & Sabrina & A \\
\hline 2345 & Beni & SI & UN125 & Bahasa Indonesia & Una &
\end{tabular}

Dari tabel di atas masih terdapat atribut yang muncul secara berulang, untuk itu harus melanjutkan ke tahap normalisasi kedua.

\section{3) Bentuk Normal Tahap Kedua (2nd Normal Form)}

a) Bentuk normal 2NF terpenuhi dalam sebuah tabel jika telah memenuhi bentuk 1NF, dan semua atribut selain primary key, secara utuh memiliki Functional Dependency pada primary key

b) Sebuah tabel tidak memenuhi 2NF, jika ada atribut yang ketergantungannya (Functional Dependency) hanya bersifat parsial saja (hanya tergantung pada sebagian dari primary key)

c) Jika terdapat atribut yang tidak memiliki ketergantungan terhadap primary key, maka atribut tersebut harus dipindah atau dihilangkan. Hal ini dapat dilihat pada tabel 3 di bawah ini :

Tabel 3. Tabel Kuliah Bentuk 2NF

\begin{tabular}{|c|l|c|c|}
\hline \multicolumn{4}{|c|}{ Tabel Kuliah } \\
\hline kode mtk & \multicolumn{1}{|c|}{ nama_mtk } & id dosen & nama_dosen \\
\hline T14801 & Sistem Basis Data & SSD & Surya \\
\hline T14815 & Rekayasa Perangkat Lunak & RNW & Ronal \\
\hline UN121 & Kalkulus & WHY & Wahyu \\
\hline UN125 & Bahasa Indonesia & SAB & Sabrina \\
\hline
\end{tabular}

\section{4) Bentuk Normal Tahap Ketiga (3rd Normal Form /3NF)}

a) Bentuk normal 3NF terpenuhi jika telah memenuhi bentuk 2NF, dan jika tidak ada atribut non primary key (biasa) yang memiliki ketergantungan terhadap atribut non primary key (biasa) yang lainnya.

b) Untuk setiap Functional Dependency dengan notasi X -> A, maka:

- $\quad$ X harus menjadi superkey pada tabel tersebut.

- $\quad$ Atau A merupakan bagian dari primary key pada tabel tersebut. 
Hal ini dapat dilihat pada tabel-tabel di bawah ini, yakni tabel mahasiswa, tabel dosen, tabel matakuliah dan tabel nilai.

Tabel 4 Tabel Tabel Bentuk 3NF

\begin{tabular}{|c|c|c|}
\hline \multicolumn{3}{|c|}{ Tabel Mahasiswa } \\
\hline$\underline{\text { nim }}$ & nama & prodi \\
\hline 1234 & Roma & TI \\
\hline 2345 & Beni & SI \\
\hline
\end{tabular}

\begin{tabular}{|c|c|}
\hline \multicolumn{2}{|l|}{ Tabel Dosen } \\
\hline id dosen & nama_dosen \\
\hline SSD & Surya \\
\hline RNW & Ronal \\
\hline WHY & Wahyu \\
\hline SAB & Sabrina \\
\hline
\end{tabular}

\begin{tabular}{|c|c|c|}
\hline \multicolumn{3}{|l|}{ Tabel Nilai } \\
\hline$\underline{\text { nim }}$ & kode mtk & nilai \\
\hline 1234 & TI4801 & A \\
\hline 1234 & TI4815 & C \\
\hline 2345 & TI4801 & B \\
\hline 2345 & UN121 & B \\
\hline 2345 & UN125 & A \\
\hline
\end{tabular}

Selanjutnya langkah kelima dilakukan pengecekan composite dan multivalue attribute dengan cara melihat data yang mengandung tanda koma. Jika tidak ada data yang mengandung nilai koma, maka tabel yang dihasilkan tetap dan proses normalisasi selesai, dan tabel dapat diimplementasikan ke database relational.

\section{PENUTUP}

Untuk melakukan normalisasi tabel pada database yang sudah diimplementasikan pada Relasional Database Management System (RDBMS). Hasil uji coba menunjukkan formula yang disajikan telah mampu melakukan normalisasi tabel hingga bentuk 3NF. Teknik yang disajikan dapat digunakan untuk melakukan normalisasi tabel yang sudah diimplementasikan pada RDBMS yang lain.

\section{DAFTAR PUSTAKA}

Bahmani A., Naghibzadeh, M. and Bahmani, B., "Automatic database normalization and primary key generation", Niagara Falls Canada IEEE, 2008

Date C.J., "Pengenalan Sistem Basis Data jilid 1", PT.Indeks Group Gramedia, 2004

Demba M, “An Algorithmic Approach to Database Normalization", International Journal of Digital Information and Wireless Communications (IJDIWC) 3(2): 197-205, The Society of Digital Information and Wireless Communications, 2013 (ISSN: 2225-658X)

Elmasri \& Navathe. "Fundamentals of Database Systems", Addison-Wesley, 2003

Fathansyah, Basis Data, Bandung: Informatika, 2012 